\title{
S5ynthesis
}

International Scientific Conference of IT and Business-Related Research

\section{AGGREGATION FUNCTIONS AS A BASIS FOR DECISION MAKING}

\author{
ZNAČAJ AGREGATNIH FUNKCIJA U PROCESU ODLUČIVANJA \\ Endre Pap \\ Singidunum University, Danijelova 32, Belgrade, Serbia \\ Obuda University, Institute of Intelligent Engineering Systems, H-1034 Budapest, Hungary
}

\begin{abstract}
:
When making the decision in various fields, the following types of uncertainties are frequently encountered: ignorance of the phenomenon; imprecision of measurement; the vagueness of language; subjective assessment. Combining information from different sources in a single important output is a crucial task of numerous investigations, mostly based on powerful computers. The paper presents the mathematical models based on aggregation functions for these uncertainties such as probability theory and statistics (by copulas), and newer mathematical methods such as the theory of fuzzy sets and fuzzy logics, and nonadditive measures and integrals based on them. A generalization of the utility theory is given based on pseudo-additive measures.
\end{abstract}

\section{Key words:}

aggregation function, triangular norm, pseudo-additive measure, fuzzy system, decision making.

\section{Acknowledgements.}

The author was supported by MPNS 174009 and "Mathematical models of intelligent systems and their applications" by the Provincial Secretariat for Science and Technological Development of Vojvodina.

\section{INTRODUCTION}

Decision making concerns decision under multiple criteria or multiple attributes, multiperson decision making, and multiobjective optimization, see (Arrow, 1963; Bouchon-Meuner, 1998; Fishburn,1970; Fodor and Roubens, 1994; Luce and Raiffa, 1958; Parmigiani and Inoue, 2009; Quiggin, 1993; Tapan, 1997). Decision making is usually based on aggregating scores or preferences, obtained from different decision makers (voters, experts, etc.), on a given set of alternatives. Therefore, it is important to have a wide range of aggregation functions (operators), knowing their propert ies and having methods for their constructions (Aczel, 1996; Grabisch et al., 2009; Pap, 2002a; Rudas, Pap, \& Fodor, 2013).

The paper presents the mathematical models based on aggregation functions for these uncertainties as probability theory and statistics (by copulas), and newer mathematical methods as theory of fuzzy sets and fuzzy logics, and non-additive measures and integrals based on them. A generalization of the utility theory is presented based on pseudo-additive measures. We shall give only a short introduction to the theory of aggregation functions (Section 2), by stressing some important classes of them, such as triangular norms and conforms, copulas. Joint distribution functions in the theory of probability are based on copulas (Section 3). A short part of the theory of fuzzy sets is

\section{Apstrakt:}

Prilikom donošenja odluka u različitim oblastima susrećemo se sa brojnim nesigurnostima poput nedovoljnog poznavanja pojave, nepreciznosti merenja, jezičke neodređenosti, subjektivne procene. predstavlja glavni zadatak brojnih istraživanja, uglavnom na jakim računarima. U radu su prikazani matematički modeli na osnovu agregatnih funkcija za date neodređenosti, poput teorije verovatnoće i matematičke statistike (preko kopula), kao i novije matematičke metode kao što su teorija fazi skupova i fazi logika, i neaditivne mere $\mathrm{i}$ integrale zasnovane na njima. Izvršena je generalizacija teorije korisnosti na osnovu pseudo-aditivnih mera.

\section{Ključne reči:}

agregatna funkcija, trougaona norma, pseudo-aditivne mere, fazi sistem, odlučivanje. Kombinovanje informacija iz različitih izvora u jedinstven prikaz

presented in Section 4. Special attention is devoted to non-additive measures and corresponding integrals, such as Choquet and Sugeno (Section 5). This important utility theory is generalized in Section 6.

\section{AGGREGATION FUNCTIONS}

Aggregation function (operator) is a function $\mathbf{A}: \bigcup[0,1]^{n} \rightarrow[0,1]$ such that the following hold

(i) $\mathbf{A}\left(x_{1}, x_{2}, \ldots, x_{n}\right) \leq \mathbf{A}\left(y_{1}, y_{2}, \ldots, y_{n}\right)$ when $x_{i} \leq y_{i}$ for every $i \in\{1,2, \ldots, n\}$,

(ii) $\mathbf{A}(x)=x$ for every $x \in[0,1]$,

(iii) $\mathbf{A}(0,0, . ., 0)=0$ and $\mathbf{A}(1,1, . ., 1)=1$.

Aggregation functions are classified in three classes: conjunctive, disjunctive and internal operators, depending on whether the value of the operator is always less than the minimum or greater than the maximum or between the minimum and maximum arguments, respectively. A mixed type of aggregation functions is also considered. Internal aggregation operators are often called compensatory operators; in this case, the bad (or good) result of one criterion can be compensated with good (or bad) results of the second criterion, so that the final result is an average value. For many different applications, we mention two special important classes of aggregation functions: triangular norms and conorms, copulas. 
A function $T:[0,1]^{2} \rightarrow[0,1]$ is triangular norm (brieflyt-norm) if for every $x, y, z \in[0,1]$ we have (T1) $T(x, y)=T(y, x)$ (commutativity), (T2) $T(T(x, y), z)=T(x, t(y, z))$ (associativity), (T3) $\mathrm{x} \leq \mathrm{y}$ $\Rightarrow T(x, z) \leq T(y, z)$ (monotonicity), (T4) $T(x, 1)=x$ (neutral element 1). Four basic t-norms are: $T_{M}(x, y)=\min (x, y)$, minimum $\mathrm{t}$-norm, $T_{P}(x, y)=x \cdot y$, product $\mathrm{t}$-norm, $T_{L}(x, y)=\max (x+y-1,0)$, Lukasiewicz t-norm,

$$
T_{D}(x, y)=\left\{\begin{array}{cc}
0 & \text { if }(x, y) \in[0,1]^{2} \\
1 & \text { others. }
\end{array}\right.
$$

A function $S:[0,1]^{2} \rightarrow[0,1]$ is $t$-conorm if there exists a $t$-norm $T$ such that for every $x, y \in[0,1]^{2}$ we have $S(x, y)=1-T(1-x, 1-y)$ (dual pair). Four basict-conorms are: $S_{M}(x, y)=\max (x, y)$ - maximum $t$ conorm, $S_{P}(x, y)=x+y-x \cdot y$ - probabilistic sum, $S_{L}(x, y)=\min (x+y, 1)$ - bounded sum,

$$
S_{D}(x, y)=\left\{\begin{array}{lr}
1 & \text { if }(x, y) \in[0,1]^{2} \\
\max (x, y) & \text { others. }
\end{array}\right.
$$

Dual pairs are $\left(T_{M} S_{M}\right),\left(T_{P}, S_{P}\right),\left(T_{L}, S_{L}\right),\left(T_{D}, S_{D}\right)$ Twodimensional copula is a binary operation $\mathrm{C}:[0,1]^{2} \rightarrow[0,1]$ such that for every $x, x^{*}, y, y^{*} \in[0,1]$ with the property $x \leq x^{*}$ and $y \leq y^{*}$, we have $C(x, y)+C\left(x^{*}, y^{*}\right) \geq C\left(x, y^{*}\right)+C\left(x^{*}, y\right), C(x, 0)=C(0, x)=0$, $C(x, 1)=C(1, x)=x$.

There is a software package called AOTool for many applications, which can be freely downloaded from http://www. deakin.edu.au/gleb/aotool.html=.AOTool. It very useful for the construction of aggregation functions based on the empirical data.

\section{JOINT DISTRIBUTION FUNCTION}

The classical multivariate statistics is based on the multivariate Gaussian distribution. The importance of copulas is stressed by the following theorem which gives new results and applications.

Sklar theorem: Let $X$ and $Y$ be random variables (with marginal distribution functions $F X, F Y$, respectively), with joint distribution function HXY. Then there exists a copula $C$, such that $H X Y(x, y)=C(F X(x), F Y(y))$. If $F X$ and $F Y$ are continuous functions, then $C$ is unique. Contrary, if FX and FY are distribution functions for random variables $X$ and $Y$, then the function $H X Y$ given by the previous formula is the joint distribution function for random vector $(X, Y)$ with marginal distribution functions $F X$ and FY.

The importance of dependence modeling with copulas is the fact that for continuous multivariate distributions, the modeling of the univariate marginals and the multivariate or dependence structure can be separated and represented by copula. For further results and applications see (Joe 2015; Nelsen, 1999).

\section{FUZZY SYSTEMS}

In order to describe situations when it is not clear whether an element belongs to the set, a generalization of the set in the sense that the affiliation element is given by a certain degree is introduced. Fuzzy subset $A$ of $X$ is given by membership function $\mu_{A}: X \rightarrow[0,1]$, where the value $\mu_{A}(x)$ is interpreted as a degree of belonging $x \in X$ to fuzzy set A, see (Grabisch, Nguyen \& Walker, 1995; Klement, Mesiar \& Pap, 1996; Pap, 1999; Pap, 2000a). Instead of $\mu_{A}(x)$, we use also the notation $A(x)$. The set of all fuzzy subsets of $X$ is denoted by $F(X)$.
Definition. Let $A \in F(X)$. Then: $A$ is normed if $(\exists x \in X)$ $(A(x)=1)$; support of $A$ is given by $\operatorname{supp}(A)=\left\{x \in X \mid \mu_{A}(x)>0\right\}$; kernel of $A$ is given by $\operatorname{ker}(A)=\left\{x \in X \mid \mu_{A}(x)=1\right\}$; a-level of $A$ is given by

$$
[\mathrm{A}]^{\alpha}=\left\{\begin{array}{cc}
x \in X \mid \mu_{A}(x)>\alpha & \text { if } \alpha>0 \\
\operatorname{cl}(\operatorname{supp}(\mathrm{A}) & \text { if } \alpha=1,
\end{array}\right.
$$

where $\operatorname{cl}(\operatorname{supp}(A))$ is the closure of the support of $A$; a fuzzy set $A$ is convex if $[A]^{\alpha}$ is a convex subset of $X$ for all a. For $A \in F(X)$ we define $\operatorname{ker}(A)=[A]^{1}$, and

$$
\operatorname{supp}(A)=\bigcup_{\alpha \in[0,1]}[A]^{\alpha},[A]^{0}=X
$$

Definition. Let $A, B \in F(X) . A$ and $B$ are equal $(\mathrm{A}=\mathrm{B})$, if $\mu_{A}(x)=\mu_{B}(x)(x \in X)$, and $A$ is a subset of $B,(A<B$ or $A \subset B)$, if $\mu_{A}(x)<\mu_{B}(x)(x \in X)$.

Knowing all $\alpha$-levels for $A \in F(X)$, the fuzzy set $A$ can be reconstructed in the following way $\mu_{A}(x)=\sup \left\{\min \left(\alpha, 1_{[A]^{\alpha}}(x)\right)\right.$ $\alpha \in] 0,1]\}(x \in X)$, where is the characteristic function of the crisp set $[A]^{\alpha}$.

At the beginning of the theory of fuzzy sets, operations with fuzzy sets were based on two operations: min and max. Today, many different types of continuous t-norms and t-conorms are used. We introduce fuzzy intersection $\cap_{T}$, fuzzy union $\cup_{S}$, fuzzy complement $C_{N}$ on $F(X)$, based on t-norm $T$, t-conorm $S$, and negationi $N$ (standard negation $\mathrm{N}(\mathrm{x})=1-\mathrm{x}$ ), respectively, (Klement, Mesiar, Pap, 2000) in the following way:

$$
\mu_{A \cap \cap_{\mathrm{T}}^{\mathrm{B}}}(x)=\mathrm{T}\left(\mu_{A(x)}, \mu_{B(x)}\right), \mu_{A \cap \mathrm{S}} \mathrm{B}(x)=\mathrm{S}\left(\mu_{A(x)}, \mu_{B(x)}\right), \mu_{C_{N^{A}}}(x)=\mathrm{N}\left(\mu_{A(x)}\right)
$$

More details on the triple (T,S,N) and on the structure $\left(F(X), \cap_{T}, \cup_{S}, C_{N^{p}} 0,1\right)$ can be found in (Klement, Mesiar \& Pap 2000). The theory of fuzzy sets and fuzzy logics have a wide range of applications through fuzzy systems: approximate reasoning, fuzzy controllers, data analysis, pattern recognition, image analysis, decision theory, optimization,economy and game theory, connections with neural networks and genetic algorithms. We mention here only two recent applications based on linear fuzzy space (Obradović et al., 2011; Obradović et al., 2013) in analyzing the satellite images, location of roads in robotics, and analyzing images in medicine. There are many useful computer programs which have adapted fuzzy sets, e.g. Fuzzy Toolbox of Matlab.

\section{NON-ADDITIVE MEASURES AND CORRESPONDING INTEGRALS}

Non-additive measures, as a generalization of the classical measure, have the advantage that they enable modeling situations where events are overlapping, e.g., (Ishii and Sugeno, 1985). LetAbe a $\sigma$-algebra of subsets of the set $X$.

Definition. Monotone (fuzzy) measure $m$ on $X$ is a monotone set function defined onAwith values in $[0, \infty]$ which is zero on empty set.

Instead of the notation $\mathrm{m}$, we shall also use the notation $\mu$ (do not mix with the same notation for membership function for fuzzy set). For more details see (Denneberg, 1994; Pap, 1995; Pap, 2002b; Wang \& Klir, 1992).

Example. Let Sbe a continuous t-conorm. A mapping $\mathrm{m}$ : $\mathrm{A} \square[0,1]$ is a pseudo-measure, if $m(\varnothing)=0, m(X)=1$, and for all $\mathrm{A}, \mathrm{B} \in \mathrm{A}, \mathrm{A} \cap \mathrm{B}=\varnothing$, it hold $m(A \cup B)=S(m(A), m(B))$.

There are important integrals based on non-additive measures in many applications. We shall here mention two types of 
integrals for finite cases. Let $\mu$ be a monotone measure on $X$ and $f$ a function defined on $X$ and with values in the set of nonegative real numbers and with finite set of values $\left\{a_{1}, a_{2}, \ldots, a_{n}\right\}$, where $a_{1}<a_{2}<\ldots<a_{n}$. Choquet integral $(C) \int f(x) d \mu(x)$ for the finite case (or simply $(C) \int f d \mu$ ) is defined by

$$
\text { (C) } \int f d \mu=\sum_{i=1}^{n}\left(a_{i}-a_{i-1}\right) \cdot \mu\left(\left\{x \mid f(x) \geq a_{i}\right\}\right) \text {. }
$$

Let be normalized fuzzy measure on $X$ and $f$ is a function on $X$ with values $\left\{a_{1}, \ldots, a_{n}\right\}$, where $0 \leq a_{1} \leq, \ldots, \leq a_{n} \leq 1$. Sugeno integral $(S) \int f(x) \mu(x)$ (or briefly $\left.\left.(S) \int f o \mu\right)\right)$ is given by (finite case)

$$
(S) \int f \circ \mu=v_{i=1}^{n}\left[a_{i} \wedge \mu\left(\left\{x \mid f(x) \geq a_{i}\right\}\right)\right] .
$$

We highlight here that Choquet integral is often used as an aggregation function, see (Grabisch, 1996; Grabisch \& Labreuche, 2008) and the edited monograph (Grabisch, Murofushi \& Sugeno, 2000).

For the purpose of the identification of the fuzzy measure by applications of Choquet integral, it is useful to use the softwer Kappalab http://www. stat. auckland. ac. nz/ivan/kappalab.

\section{HYBRID UTILITY}

Special attention is devoted to hybrid utility theory as generalization of the classical approach. The basic mathematical tool under uncertainty was based on the probability, see (von Neumann \& Morgenstern, 1944). However, its practical application has been, and still is, extremely limited. In order to generalize the decision theory, and therefore the utility theory, it was necessary to get out of probability framework generalizing the set of measures. This part of the paper is based on the work of Dubois, Pap and Prade (2000), which is related to hybrid probabilistic possibilistic measure, for which it is proved that it is a limit in the generalization, under which the properties of the utility function would be lost. The paper (Dubois, Pap \& Prade, 2000) gives an answer to the question on how to generalize the existing theory of utility and such obtained generalization improves the application of this theory in practice. The aim of the study was to determine the appropriate axiomatic based on a hybrid probabilistic - possibilistic measure. $T$ is conditionaly distributive over $S$ if for every $x, y, z \in[0,1]$ we have (Klement, Mesiar \& Pap, 2000a)

$T(x, S(y, z))=S(T(x, y), T(x, z))(\mathrm{CD})$, under the condition $S(y, z)<1(\mathrm{CD})$.

Theorem. A continuous $t$-norm $T$ and a continuous $t$-konorm $S$ satisfy the condition (CD) if and only if one of the following two casesoccur:

(i) $S=S M$

(ii) There exists a strict $t$-norm $T^{*}$ and a nilpotent $t$-konorm $S^{*}$ such that the additive generator $s$ of $S^{*}$ such that $s(1)=1$ is also a multiplicative generator of $T^{*}$, and there exists $a \in\left[0,1\right.$ [ such that for some continuous $t$-norm $T^{* *}$ we have the ordinal sum representations $T=\left(\left\langle 0, a, T^{* *}\right\rangle,\left\langle a, 1, T^{*}\right\rangle\right)$ and $\left.S=\left(<a, 1, S^{*}\right\rangle\right)$, see (Klement, Mesiar, Pap, 2000a).

The result of the preceding theorem is illustrated in Figure 1 (using the existing isomorphisms).

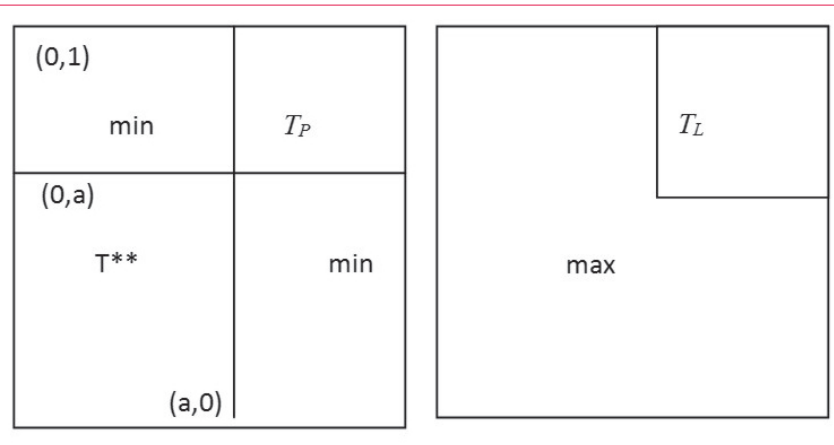

Figure 1. $\left.\left.\mathrm{T}=\left(<0, a, T^{* *}\right\rangle,<a, 1, T^{*}\right\rangle\right)$ (left)and $\left.S=\left(<a, 1, S^{*}\right\rangle\right)$ (right).

As a generalization of the theory of von Neumann and Morgenstern, optimistic hybrid utility function is introduced (Duboisa, Pap \& Prade, 2000):

$$
U(u 1, u 2 ; w 1, w 2)=S(T(u 1, w 1), T(u 2, w 2))
$$

where $u 1$ and $u 2$ are two utility values in $[0,1]$ and $w 1$ and $w 2$ are two degrees of plausibility from the set

$$
\{(r, s): r, s \in] a, 1[, r+s=1\} \cap\{(r, s): \min (r, s) \leq a, \max (r, s)=1\} .
$$

This utility function is examined in detail, and it can be given an interpretation related the behavior of the decision maker. Namely, if $w 1>a$ and $w 2>a$, then the decision maker is very uncertain about the state of nature: both $w 1$ and $w 2$ are high and the two involved states have high plausibility. Subcase $u 1>a$ and $u 2>a$ gives that the reward is high in both states, and then the behavior of utility is probabilistic. Subcase $u 1 \leq a$ and $u 2>a$ (same for the case $u 1>a$ and $u 2 \leq a$ ) is when the reward is low in one state but high in the other state. Then, the decision-maker looks forward to the best outcome and the utility is a function of $u 2$ and $w 2$ only. In case $u 1 \leq a$ and $u 2 \leq a$ both rewards are low, and the decision maker is possibilistic and again focuses on the best outcome. Now, the first state is unlikely, i.e., $w 1 \leq a$ and $w 2=1$. Then, for $u 1>a$ and $u 2>a$ (also for $u 1 \leq a$ and $u 2>a$ ) is a situation when the plausible reward is good, then the decision maker looks forward to this reward. Subcase $u 1>a$ and $u 2 \leq a$ shows that the most plausible reward is low, then the decision maker still keeps some hope that the first state will prevail if $u 2$ is really bad, but weakens the utility of the first state, because it lacks plausibility. This phenomenon subsides when the least plausible outcome is also bad, but the (bad) utility of the first state participates in the calculation of the resulting utility, by discounting $w 1$ even further.

\section{SUMMARY}

We have provided a short overview on applications of some actual aggregation functions as triangular norms, triangular conorms and copulas. These applications of copulas are related to the theory of joint distribution functions, whose investigations are today very popular because of the need of modeling complex situations in many fields. Applications of triangular norms were illustrated in the theory of fuzzy sets, where many real applications occur. Non-additive measures serve as a base for important aggregation functions named fuzzy integrals covering Choquet and Sugeno integrals. Finally, special pairs of triangular norms and triangular conforms and pseudo-additive measures enable generalization of the classical utility theory of von Neumann and Morgenstern. 


\section{REFERENCES}

Aczel, J. (1996). Lectures on Functional Equations andtheir Applications. New York: Academic Press.

Arrow, K. J. (1963). Social Choice and Individual Values. New Haven, CT: Yale University Press.

Bouchon-Meuner, B. (1998). Aggregation and Fusion of Imperfect Information. Heidelberg: Springer-Verlag.

Denneberg, D. (1994). Non-additive Measure and Integral. Theory and Decision Librarary, Vol. 27, Series B: Mathematical and Statistical Methods. Dordrecht: Kluwer Academic Publishers Group.

Dubois, D., Pap, E., \& Prade, H. (2000). Hybrid probabilisticpossibilistic mixtures and utility functions, In: B. De Baets, J. Fodor, P. Perny (Eds. ) Preferences and Decisions under Incomplete Knowledge, Springer-Verlag, 51-73.

Fishburn, P. (1970). Utility theory for decision making. New York: Wiley.

Fodor, J. C., \& Roubens, M. (1994). Fuzzy Preference Modeling and Multi: Criteria Decision Aid. Dordrecht: Kluwer Academic Publisher.

Grabisch, M. (1996). The application of fuzzy integrals in multicriteria decision making. European Journal of Operational Research, 89(3), 445-456. DOI: 10. 1016/0377-2217(95)00176-X

Grabisch, M., \& Labreuche, C. (2008). A decade of application of the Choquet and Sugeno integrals in multi-criteria decision aid. $4 O R, 6(1), 1-44$.

Grabisch, M., Marichal, J. L., Mesiar, R., \& Pap, E. (2009). Aggregation Operators. Cambridge: Cambridge University Press.

Grabisch, M., Murofushi, T., \& Sugeno, M. (2000). Fuzzy Measures and Integrals: Theory and Applications. Heidelberg: Physica-Verlag.

Grabisch, M., Nguyen, H.T., \& Walker, E.A. (1995). Fundamentals of Uncertainity Calculi with Application to Fuzzy Inference, Kluwer Academic Publishers, Dordrecht/Boston/ London.

Ishii, K., \& Sugeno, M. (1985). A Model of Human Evaluation Process Using Fuzzy Measure. International Journal of Man-Machine Studies, 22(1), 19-38. DOI: 10. 1016/S00207373(85)80075-4.

Joe, H. (2015). Dependence Modeling with Copulas. Boca Raton: CRC Press.

Klement, E.P., Mesiar, R., \& Pap, E. (1996). On the Relationship of Associative Compensatory Operators to Triangular Norms and Conorms. International Journal of Uncertainty: Fuzziness and Knowledge Based Systems 4(2), 129-144.
Klement, E. P., Mesiar, R., \& Pap, E. (2000). Triangular Norms. Dordrecht: Kluwer Academic Publishers.

Luce, R. D., \& Raiffa, H. (1958). Games and Decisions. New York: Wiley.

Murofushi, T., \& Sugeno, M. (1993). Some quantities represented by the Choquet integral. Fuzzy Sets and Systems, 56, 229235.

Nelsen, R. B. (1999). An Introduction to Copulas, volume 139 Lecture Notes in Statistics. New York: Springer-Verlag.

Obradović, Đ., Konjović, Z., Pap, E., \& Rudas, I. J. (2013). Linear Fuzzy Space Based Road Lane Detection. Knowledge Based Systems, 38, 37-47.

Obradović, Đ., Konjović, Z., Pap, E., \& Ralević, N. (2011). The maximal distance between imprecise point objects. Fuzzy Sets and Systems, 170, 76-94.

Pap, E. (1995). Null-Additive Set Functions. Dordrecht: Kluwer Academic Publishers.

Pap, E. (1997). Pseudo-analysis as a mathematical base for soft computing. Soft Computing, 61-68.

Pap, E. (1999). Fazi mere i njihova primena. Novi Sad: Prirodnomatematički fakultet.

Pap, E. (2002a). Aggregation operators in the engineering design. In C. Tomasa, G. Mayor, R. Mesiar (Eds. ) volume 97 of Studies in Fuzziness and Soft Computing, Springer-Verlag, 195-223.

Pap, E. (2002b). Handbook of Measure Theory: Volume I, II. North-Holland: Elsevier.

Parmigiani, G., \& Inoue, L. (2009). Decision Theory: Principles and Applications. New York: Wiley.

Quiggin, J. (1993). Generalized Expected Utility Theory. Boston: Kluwer Academic.

Rudas, I. J., Pap, E., \& Fodor, J. (2013). Information aggregation in intelligent systems: An application oriented approach. Knowledge Based Systems, 38, 3-13.

Saaty, T. L. (1978). Exploring the interfaces between hierarchies, multiple objectives and fuzzy sets. Fuzzy Sets and Systems 1, 57-68.

Tapan, B. (1997). Decision Making under Uncertainty. London: Macmillan Press.

von Neumann, J., \& Morgenstern, O. (1944). Theory of Games and Economic Behaviour. Princeton, NJ: Princeton University Press.

Wang, Z., \& Klir, G. J. (1992). Fuzzy Measure Theory. New York and London: Plenum Press. 